\title{
Planejamento de restauro de qualidade ecológica de duas ribeiras litorais
}

\author{
Restoration plan of the ecological quality of two coastal streams
}

Terencio Aguiar Junior ${ }^{1}$, Leonardo Werneck Ceolin ${ }^{2}$

口-

\begin{abstract}
RESUMO
Este trabalho faz parte de um projeto de restauro de bacias e baseia-se em uma pré-classificação do estado ecológico das mesmas através da metodologia KT, que permite a divisão do sistema fluvial em segmentos fluviais designados Unidades Fisiográficas Homogêneas e a identificação do nível de degradação dos mesmos através da mensuração das pressões humanas locais. A partir dos dados obtidos, podem ser propostas as medidas de recuperação fluvial necessárias para um "bom estado" ecológico de cada unidade. O projeto busca cumprir os objetivos das convenções internacionais de proteção ao meio ambiente e atingir as metas da Diretiva Quadro da Água. Este trabalho desenvolve uma carta sintética expondo o estado de conservação dos segmentos fluviais das bacias da Ribeira do Falcão e da Ribeira da Mata (região das Ribeiras do Oeste, Litoral Centro de Portugal), caracterizando e quantificando o seu nível de degradação, identificando suas respectivas causas e propondo soluções.
\end{abstract}

Palavras-chave: restauro fluvial; gestão e conservação; ecossistemas aquáticos; pressões humanas.

\begin{abstract}
This working paper is part of a watershed restoration project and is based on a pre-classification of ecological status of same by KT methodology, which allows the division of the river system in river segments designated Physiographic Units Homogeneous and identifies the level of their degradation by measuring the local human pressures. From the data obtained may be proposed river restoration measures needed for a "good status" of each ecological unit. The project seeks to achieve the objectives of international conventions to protect the environment and achieve the goals of the Water Framework Directive. This paper develops a synthetic letter exposing the state of conservation of the segments of the river basins of the Hawk and Ribeira da Mata da Ribeira (Ribeira region of West, Central Coast of Portugal), characterizing and quantifying the level of degradation, identifying their respective causes and proposing solutions.
\end{abstract}

Keywords: river restoration; management and conservation; aquatic ecosystems; human pressures.

\section{INTRODUÇÃO}

Um dos desafios enfrentados pela humanidade nos dias atuais decorre da dicotomia, que os defensores do desenvolvimento sustentável consideram falsa, entre o desenvolvimento tecnológico e a preservação dos recursos naturais. No âmbito desta questão, encontra-se a necessidade de um manejo adequado dos recursos hídricos devido à sua importância para a nossa sobrevivência, uma vez que a água é o principal constituinte de todos os organismos vivos e o motor principal do desenvolvimento humano (MUHAR, 1996).

Nos últimos 60 anos, a população mundial duplicou, enquanto o consumo de água multiplicou-se por 7 (AGUIAR JUNIOR \& CEOLIN, 2011). Tendo em vista que de toda a água existente no planeta $97 \%$ são salgadas (mares e oceanos), e que $2 \%$ formam geleiras inacessíveis, resta apenas 1\% de água doce, armazenada em lençóis subterrâneos, rios e lagos, distribuídos desigualmente pela Terra (CORTES et al., 2002). A água é um bem não renovável e, na prática, o aumento populacional tem ocorrido em muitas zonas em níveis superiores aos tolerados pela natureza, resultando em stress do sistema hídrico.

Estima-se que no início deste século mais da metade da população mundial viverá em zonas urbanas. Até o ano 2025, a proporção chegará aos $60 \%$, compreendendo cerca de 5 bilhões de pessoas (CORTES et al., 2002).

$\mathrm{O}$ crescimento rápido da população urbana e da industrialização está submetendo os recursos hídricos a grandes pressões em muitas áreas de cidades em todo o planeta. E nos espaços rurais, a agricultura intensiva, com o uso de fertilizantes químicos, irrigação e ocupação de zonas ribeirinhas, também exerce pressão sobre os recursos hídricos,

'Doutor em Ecologia de Ecossistemas. Investigador da Universidade Técnica de Lisboa. ${ }^{2}$ Doutorando em Recursos Hídricos pela Universidade Técnica de Lisboa.

Endereço para correspondência: Terencio Rebello de Aguiar Junior - Instituto Superior de Agronomia - Tapada da Ajuda - 1349-050 - Lisboa, Portugal - E-mail: terenciojunior@isa.utl.pt Recebido: 11/07/12 - Aceito: 04/09/13 - Reg. ABES: 466 
causando impactos negativos (BORJA \& MORAES, 2003). Dentre eles citamos: a diminuição do nível freático com a utilização de água para irrigação além da capacidade de recarga do sistema; aumento da concentração de nutrientes nas águas superficiais e subsuperficiais, alterando a qualidade da água dos rios; o desmatamento das galerias ripícolas com seus inúmeros impactos negativos para o sistema fluvial, como erosão e sedimentação dos canais e aumento do input de nutrientes provenientes do escoamento superficial e subsuperficial; e incremento da temperatura da água pela ausência do coberto vegetal que minimiza a insolação; além de dezenas de outros impactos já conhecidos pela comunidade científica (ZALEWSKI, 2000).

O objetivo do presente trabalho foi produzir uma carta sintética relativa ao estado de conservação dos troços e segmentos fluviais das bacias da Ribeira do Falcão e Ribeira da Mata (região das Ribeiras do Oeste, Litoral Centro de Portugal) que não apenas caracterizasse e quantificasse o nível de degradação dos troços que as compõem como também identificasse suas respectivas causas. Os dados e resultados obtidos a partir desta carta poderão ser utilizados como ferramenta de apoio ao restauro ecológico do sistema fluvial, tanto ao nível do segmento quanto ao da bacia, e auxiliar na gestão ambiental das ribeiras do Falcão e da Mata. Representam também um esforço na implementação da DQA e do Plano de Gestão de Bacia Hidrográfica (PGBH), que todas as Administrações Regionais Hidrográficas têm que implementar e gerenciar nos próximos anos.

\section{Área em estudo}

A bacia da Ribeira da Mata localiza-se totalmente dentro do Parque Natural de Sintra Cascais, e a bacia da Ribeira do Falcão (Figura 1) situa-se na zona limítrofe do parque, sendo que a maior parte se sua área está contida nos seus limites, com uma faixa ao norte, já pertencente ao Concelho de Mafra. O Parque Natural de Sintra-Cascais compreende as freguesias de São Pedro de Penaferrim, Santa Maria e São Miguel, São Martinho, São João das Lampas e Colares, ao passo que em Cascais inclui as freguesias de Cascais e Alcabideche. Está inserida na região ocidental da Terra Saloia e na Área Metropolitana de Lisboa-Norte.

\section{METODOLOGIA}

O presente trabalho adota a metodologia KT, que faz a representação do sistema fluvial em troços fluviais designados Unidades Fisiográficas Homogêneas (UFHs). A rede fluvial é basicamente dividida em troços, caracterizados por um conjunto próprio de estruturas geomorfológicas visíveis a olho nu e frequentemente designados em termos de ecologia fluvial pelo sistema de erosão/sedimentação, e inclui remansos, rápidos e estruturas derivadas. A este conjunto de estruturas hidrogeomórficas que caracteriza cada troço fluvial corresponde um grupo equivalente de comunidades biológicas. Em condições naturais, o troço tem uma permanência temporal em geral superior a 100 anos, e vários troços compõem um segmento fluvial (CORTES et al., 2002; FERNANDES et al., 2007).

Como cada UFH possui

uma dada tipologia habitacional, ou seja, um mosaico de habitats estabelecido em função da hierarquia fluvial, do substrato geológico e da disponibilidade hídrica, que serão determinantes para a profundidade, fluxo e substrato do leito, cada UFH responde teoricamente da mesma forma à perturbação ou à redução desta. (AGUIAR JUNIOR, 2010; FERNANDES et al., 2007).

A classificação do estado de conservação tem início com a definição das unidades fisiográficas/tipológicas existentes, ou troços homogêneos fluviais (UFH). As variáveis utilizadas para caracterizar os tipos de troços fluviais nas bacias do Falcão e da Mata foram a geologia, a precipitação, a altitude e o número de ordem (Figura 1), que representam os três eixos ecológicos determinantes dos ecossistemas fluviais mediterrâneos: hierarquia, geomorfologia e disponibilidade hídrica. O número de ordem de Strahler está ligado à hierarquização da rede fluvial, sendo função da distância à nascente, relacionando-se com a magnitude da drenagem ao longo da bacia. Em termos biológicos, tem ligação com a sucessão longitudinal das comunidades. A geologia influencia as características físico-químicas da água em termos de concentração de nutrientes, capacidade tamponizante e transporte de sólidos, afetando, consequentemente, a produtividade primária e secundária. Já a altitude está associada ao relevo e à topografia, refletindo a forma do vale e contribuindo para as características morfométricas do troço. A precipitação determina as condições hidrológicas e as categorias de caudal, condicionando o biota.

A operação resultou em 11 sub-bacias para cada uma das bacias do Falcão e da Mata. Como sigla, quando se trata das sub-bacias ou das UFHs das duas bacias, relaciona-se a sua numeração com a letra da ribeira de origem, ou seja: de F1 a F11 para UFHs e sub-bacias do Falcão, e de M1 a M11 para as UFHs e sub-bacias da ribeira da Mata (Figura 2). As sub-bacias foram calculadas por meio do ponto médio de cada UFH.

Os troços, após a determinação de suas tipologias, podem ser classificados de acordo com o seu estado de conservação em relação a diferentes níveis de intervenção humana, e estas variáveis de perturbação conduzem a um valor final. Como base de apoio ao trabalho, utilizou-se o Sistema de Informação Gerencial (SIG), que permitiu criar uma base de dados georreferenciada para as bacias do Falcão e da Mata. Os dados foram cedidos pelo Instituto da Água (INAG) e Administração Regional Hidrográfica do Tejo (ARH) e pelo Instituto Superior de Agronomia (ISA.UTL).

Por meio das operações comuns do programa ArcGIS-9.3 foi possível integrar, gerir, criar e manipular a informação necessária para a concretização dos objetivos definidos. Ferramentas como Flow acumulation, 
A

\section{Geologia}

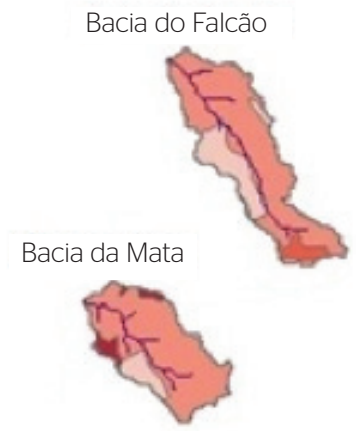

\section{Precipitação}

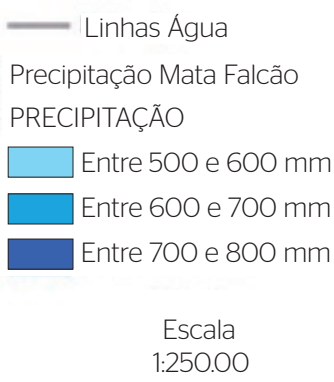

C1: complexo vulcano-sedimentar (arenitos, xistos e carbonatos);

D: quartizitos, xistos, raros.

C

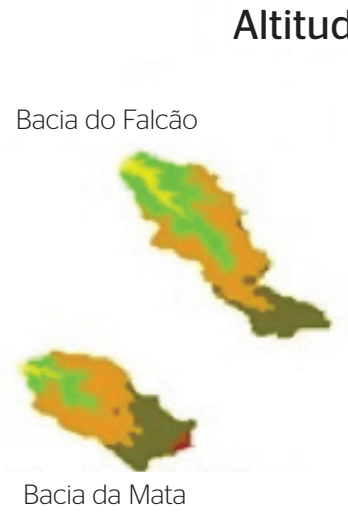

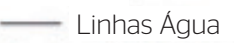

Geologia Mata Falcão

GEOLOGIA

$\square$ CIBEL
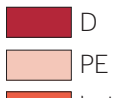

$\square$ beta

Escala

$1: 250.00$
$\AA^{N} \quad B$

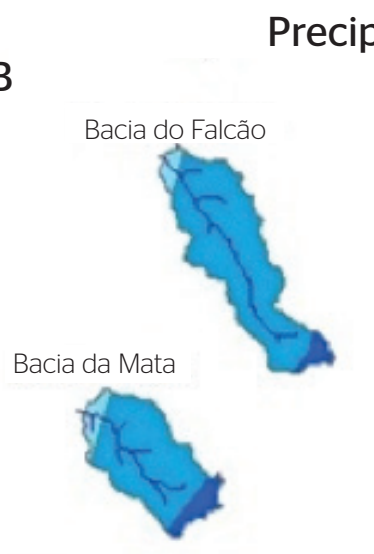

Ordem de Strahler

D
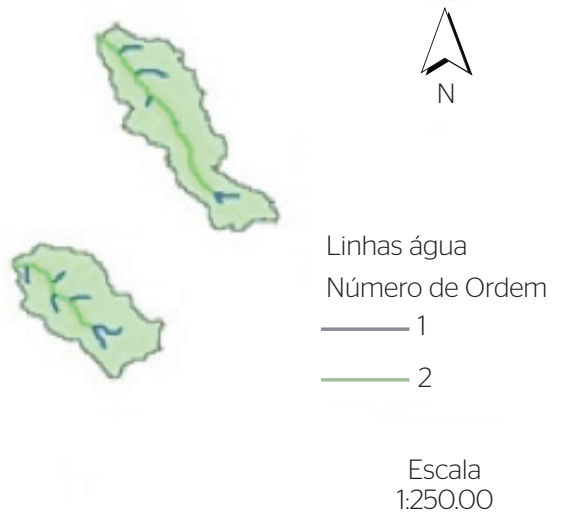

mdt Bacias

GRIDCODE

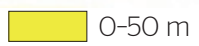

51-100 m

101-150 m

151-200 m

201-250 m

Escala

1:250.00

Figura 1 - Cartas das variáveis caracterizadoras das Unidades Fisiográficas Homogéneas nas bacias do Falcão e da Mata: (A) geologia; (B) precipitação; (C) altitude; (D) número de ordem da rede hidrográfica (Strahler).

Flow direction e Watershed foram requeridas para o cálculo das sub-bacias, e também foram utilizadas Intersection e Clip, para unir os layers e criar os mapas de caracterização biofísica das bacias do Falcão e da Mata, dentre outras contidas no programa.

As sub-bacias de cada UFH foram calculadas utilizando a ferramenta Watershed em ambiente ArcGIs. O nível de pressões humanas para cada sub-bacia (degradação, pressão) foi determinado para cada uma delas, sendo a área da pressão representada pela atuação humana, como é o caso de agricultura, estradas, barreiras, pontes, área urbana e descarga de efluentes.

Ambas as ribeiras foram percorridas ao longo do seu curso, de montante para jusante, nos dias 5 e 6 de junho de 2010, e, utilizando um GPS, foram marcados os pontos de obstrução e ocorrência de canas nas margens, sendo estes posteriormente conjugados aos dados de pressões obtidos das visualisações no Google Earth.

Como acervo digital e auxílio à classificação das variáveis K6 e K7 foi criado um ficheiro em formato Kml (Google Earth), onde foi desenvolvido um layer de pontos medidos ao longo da linha d'água, com distância linear a cada $100 \mathrm{~m}$. Em cada ponto foi medida a largura da mata ripária de ambas as margens. Foram encontrados 78 pontos para a Ribeira da Mata e 103 para a Ribeira do Falcão. Os valores e análises encontrados não só auxiliaram na classificação KT, mas também são informações relevantes a serem consideradas nas propostas de intervenção.

A metodologia empregada na criação dos pontos consistiu em partir da jusante para montante, seguindo o curso principal. A partir dos dados referentes à mata ripária foram elaborados gráficos para permitir a visualização dos valores encontrados. Os principais dados selecionados para os gráficos foram a percentagem de perda de mata por UFH e o desvio em relação aos valores da média da mata ripária de cada UFH. Estes dois eixos demonstram a quantidade perdida de mata. Nos pontos nos quais o desvio é negativo estão os valores de mata ripária a serem restaurados para igualar os da média de mata ripária de cada UFH, e nos pontos positivos, os locais a preservar (Figuras 1 e 2). O cálculo de perda de mata ripária foi realizado da seguinte forma: [Largura máxima do troço x comprimento do troço] - [Largura média do troço x comprimento do troço]. 


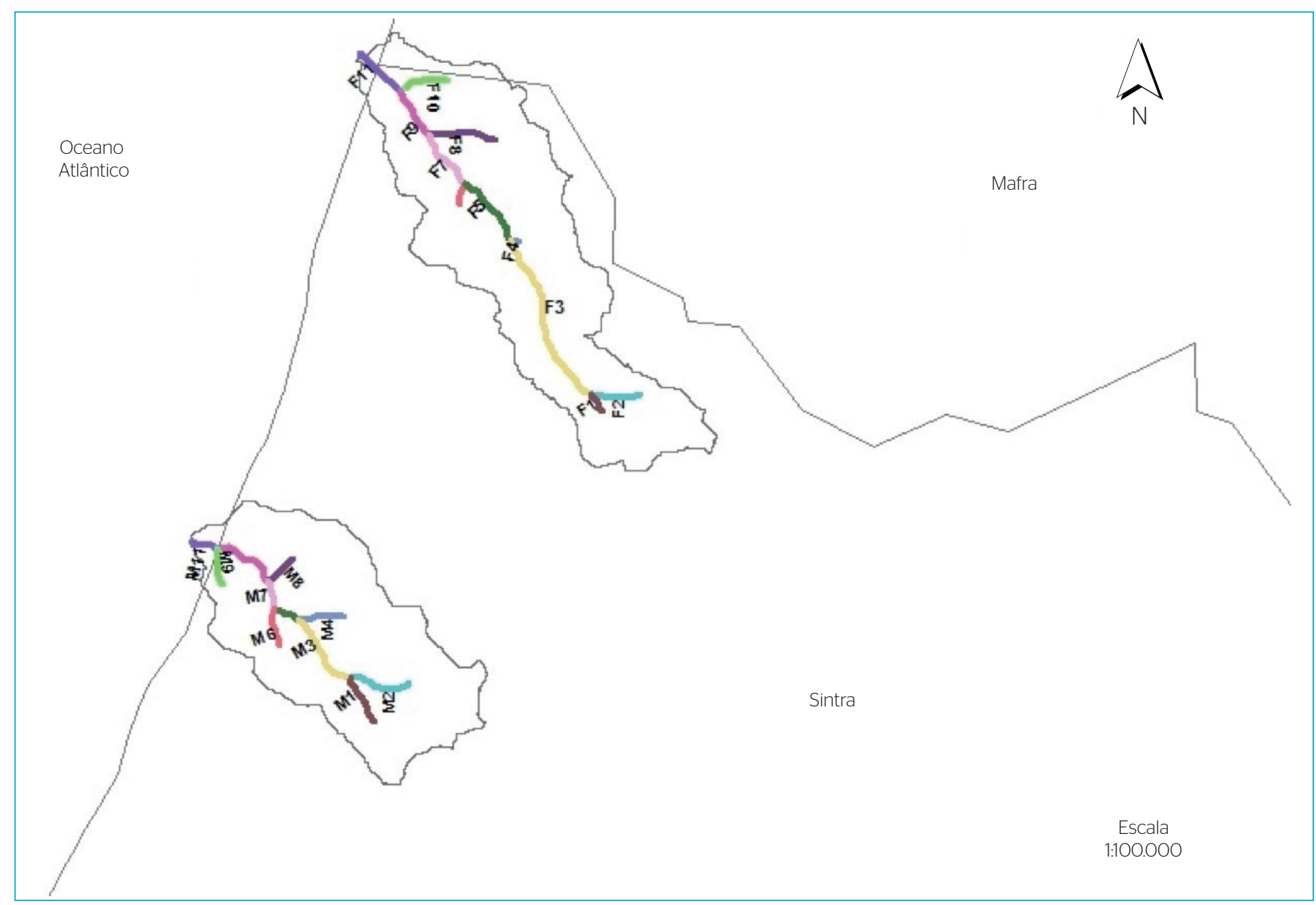

Figura 2 - Unidades Fisiográficas Homogêneas encontradas nas bacias das ribeiras do Falcão e da Mata.

Consideraram-se as seguintes variáveis de pressão, cuja metodologia de coleta de informação se encontra abaixo:

- K1 - Vias de comunicação: Adicionam no sistema fluvial poluição proveniente dos pneus dos carros, óleos e fuligem do combustível;

- K2 - Aglomerado urbano: A urbanização resulta em impermeabilização do solo e escoamento superficial mais elevado devido à menor infiltração, ocasionando enxurradas, além de toda a poluição doméstica e industrial associada ao tecido urbano;

- K3 - Fontes tópicas de poluição: A alteração na quantidade de matéria orgânica no sistema fluvial é uma das causas principais de eutrofização da massa d’água;

- K4 - Área de agricultura irrigada: Além dos impactos da própria agricultura, que serão discutidos a seguir, a irrigação aumenta a lixiviação do solo e o carreamento dos nutrientes para a linha d'água, incrementando a produtividade primária e o crescimento de algas e macrófitos;

- K5 - Área agrícola: A agricultura, de acordo com a sua intensidade e utilização de fertilizantes, vai aumentando a quantidade de nutrientes que chegam à linha d'água por meio do escoamento superficial e subsuperficial, ocasionando a eutrofização da massa d'água;

- K6 - Largura e integridade da mata ripária: Possui funções muito importantes no sistema ribeirinho, atuando como um filtro natural, impedindo a entrada dos nutrientes que chegam à ribeira por meio do escoamento superficial e subsuperficial, atuando na termorregulação de todo o sistema, no input de folhada no sistema e na proteção das margens contra erosão, diminuindo, assim, a sedimentação e consequente açoreamento do leito, dentre outras;

- K7 - Alterações morfológicas da margem e do leito, obstáculos, açudes, etc.: Importante quando se refere à conectividade longitudinal do sistema fluvial. Os peixes migradores necessitam desta conectividade para completarem o seu ciclo de vida. A construção de açudes e barreiras atua também na mudança do caudal natural, alterando o perfil de secas e cheias;

- K8 - Quantidade de margem invadida por canas: A presença de macrófitos ao longo das margens da ribeira, e dentro da massa d'água, demonstra o excesso de nutrientes, provavelmente fósforo e nitrogênio que advêm dos campos agrícolas. 
No dia 5 de junho de 2006 houve uma visita de estudo à Ribeira do Falcão, e no dia 6 de junho de 2010, à Ribeira da Mata. Ambos os trajetos iniciaram-se à montante em direção à jusante, seguindo as linhas d'água das ribeiras. Utilizando um GPS durante o percurso, foram marcados os pontos de obstrução/obstáculos no curso d'água, como pontes, manilhas e passagens, e também a presença de canas; e foi medido o comprimento dos maciços encontrados. Juntamente com os dados visualizados no Google Earth, criou-se um shapefile georreferenciado e um arquivo $\mathrm{Kml}$ que auxiliou na mensuração e classificação das variáveis de pressão.

Foi calculada a percentagem de cada pressão sobre as linhas d'água, e para a área do buffer de $100 \mathrm{~m}$ de cada UFH. Posteriormente, aplicou-se a classificação KT para obter o seu estado de conservação. Para que todos os componentes do KT tivessem importância idêntica ao serem definidas na classificação final do estado de conservação (KT), uma vez que apresentam valores muito distintos entre elas, foram agrupadas em cinco classes, variando de I (muito bom) a V (mau). O valor global da soma do Kx z tem amplitude máxima possível entre 8 e 48, mas o valor máximo encontrado foi 26 .

\section{RESULTADOS}

\section{Nível espacial da sub-bacia}

A região possui sete diferentes classes de uso do solo (Figura 3). A maior porção da superfície das bacias é composta por complexos e variados padrões de cultura (agricultura heterogénea), com áreas de vegetação natural, de florestas de coníferas, com culturas

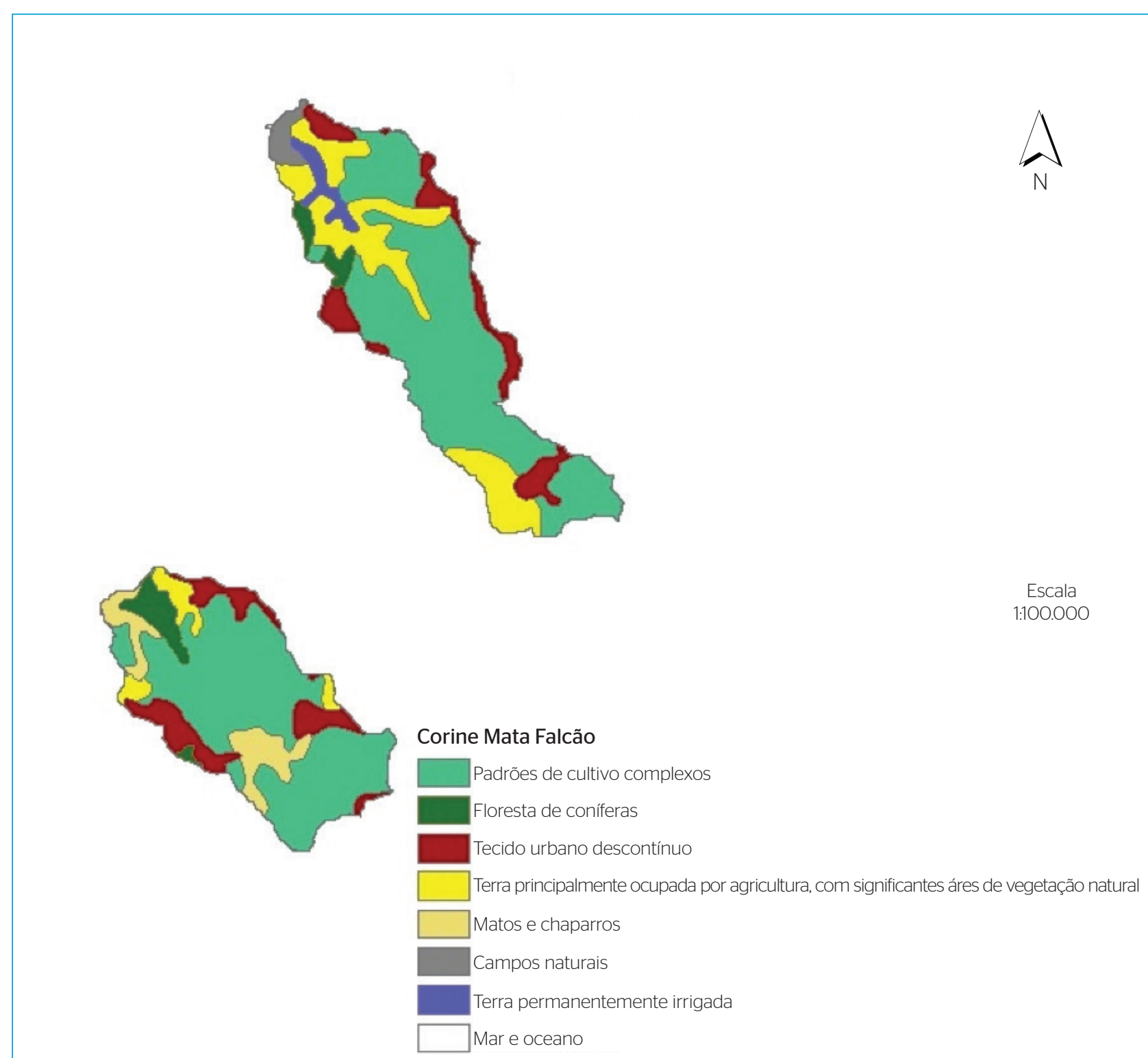

Figura 3 - Uso do solo nas bacias da ribeira da Mata e Falcão. 
e vegetação natural, de matos e chaparros, de irrigação permanente e, revelando maior pressão agrícola em relação à pressão urbana. Ambas as bacias são cortadas por estradas e sofrem, portanto, com a pressão das mesmas. A principal pressão sofrida por essas bacias é o efeito de barreira, que rompe a importante conectividade longitudinal da ribeira (Figura 3). Em outras há estradas cortando as ribeiras, que são canalizadas com manilhas.

Nos últimos 5 anos houve apenas um incêndio, em 2008, na bacia da Ribeira do Falcão, atingindo área de apenas 51,93 $\mathrm{m}^{2}$. A informação disponibilizada pela ARH sobre fontes de poluição, como suinoculturas, efluentes domésticos e efluentes industriais, entre outras, após georreferenciadas, permitiu concluir que, além das Etares de Bolelas e Magoito, não há presença de outras fontes de poluição dentro das bacias em estudo.

Nos layers de poluição do Atlas do Ambiente e em suas tabelas de atributos não há poluição industrial dentro dos limites dos divisores de águas de ambas as bacias.

No Magoito, junto à Ribeira da Mata, a fazenda faz tratamento das águas residuais provenientes de Magoito e das povoações de Bolembre, Tojeira, Fontanelas, Gouveia e outros aglomerados de menor dimensão localizados nesta bacia. A estação entrou em funcionamento em 2001 e está dimensionada para uma população de 5.197 habitantes. Dada a proximidade à zona costeira, foi previsto um sistema terciário com desinfecção do afluente final por ultravioleta. A descarga na Ribeira da Mata cumpre o estabelecido nos Decretos-Lei 236/98 e 152/97.

A fazenda localizada em Catribana, junto à Ribeira de Bolelas, trata as águas residuais provenientes de São João das Lampas e das povoações da Assafora e Odrinhas, além de outros aglomerados de menor dimensão englobados nesta bacia. A estação entrou em funcionamento em 2004 e está dimensionada para uma população de 7.535 habitantes. A descarga na Ribeira de Bolelas também cumpre o estabelecido nos Decretos-Lei 236/98 e 152/97.

\section{Nível espacial confinante do troço}

Os dados referentes às pressões humanas, contidos na área de $100 \mathrm{~m}$ no entorno da linha d'água (buffer), fazem parte dos ponderativos das variáveis de pressão KT. Com isso, aos valores encontrados dentro do buffer foi acrescentado outro (ponderativo). Por esta razão têm peso maior na classificação ecológica.

Os resultados das pressões encontrados dentro do buffer demonstram que apenas nas UFHs F1 e F2 há presença de tecido urbano. A agricultura irrigada está presente nas UFHs F7 a F11, sendo que todas UFHs possuem área agrícola, com proporções variando entre 13,31 e 94,83\%. Apenas algumas UFHs têm obstáculos e presença de canas, sendo elas a F2, F3, F5, F11, M2, M3, M5 e M9. As UFHs apresentam valores de margem careca que variam entre 6 e $34 \%$.

As Figura 4 e 5 apresentam os valores de desvio médio da mata ripária de cada UFH, variando de 1,0 (F1) a 55,6\% (M9), e de largura mínima e máxima, entre 0,0 (F2, F7, M1, M2 e M6) e 35,0 m (M9). Nelas também podem ser verificados os cálculos de área potencial e de área efetiva, obtidos com os valores do Lmáx e Lmédio, respectivamente. As percentagens de perdas calculadas por UFH variaram entre 0 (F3) e 78\% (F4).

Nas Figuras 4 e 5, o desvio da mata ripária por UFH e as áreas com valores elevados devem ser preservadas, pois possuem largura de mata ripária excepcional. Os números negativos são os pontos nos quais a mata ripária deve ser recuperada, pois apresenta largura de mata ripária inferior à média da UFH em que se localiza.

Estabeleceu-se $10 \mathrm{~m}$ como medida base tanto para os valores positivos quanto para os negativos. Assim, quando superiores a $10 \mathrm{~m}$ e inferiores a -10 m são consideradas áreas de alto valor de conservação e alta necessidade de recuperação, respectivamente. Os valores do primeiro ponto (0) de cada bacia podem ser desconsiderados nas propostas de restauro, pois tais pontos estão localizados à juzante, junto à foz das bacias, já que o estudo da

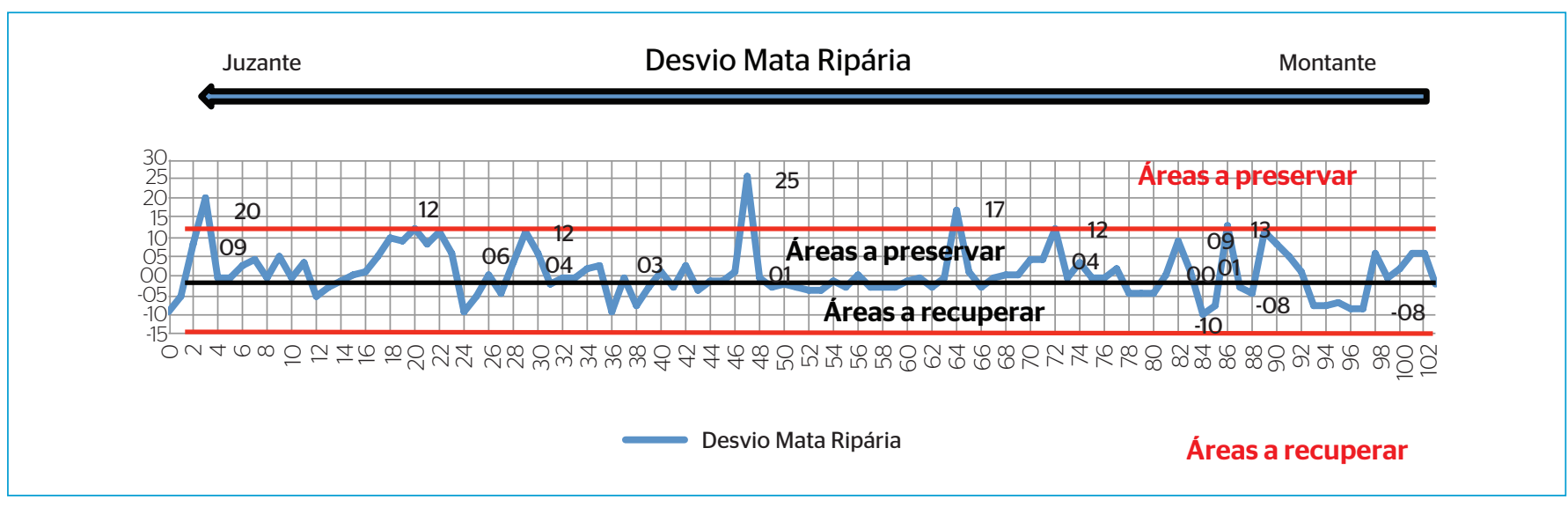

Figura 4 - Valores de desvio em relação à média de mata ripária por ponto na Ribeira do Falcão. 
mata ripária ligado à planície costeira em zonas de praias, dunas e falésias não é relevante neste estudo.

A percentagem de perda calculada foi uma maneira prática de imaginarmos a mata ripária potencial que existiria sem a intervenção humana. No entanto, não temos dados que nos forneçam valor de referência para esta época. Contudo, a maior largura encontrada em cada UFH foi considerada largura potencial do troço, e fez-se a comparação com a média por UFH da largura efetiva encontrada em cada ponto. O resultado representa valores de áreas que potencialmente fariam parte da mata ripária e, com isso, as UFHs com perdas elevadas são aquelas com maiores áreas a recuperar.

O uso da ribeira do Falcão para fins agrícolas é mais pronunciado em relação à ribeira da Mata, mas em ambas as bacias é visível o excesso de algas verdes e azuis na massa d'água. A da Mata possui massa florestal mais extensa, com áreas de carvalhos e pinheiros, matos e chaparros, em comparação à do Falcão. Sua mata ripária também inclui zonas de coberto vegetal denso, árvores com mais de $10 \mathrm{~m}$ de altura e bom sombreamento.

Parece haver, em ambas as bacias, utilização das águas das ribeiras para irrigação superior àquela apontada nos dados obtidos anteriormente. Foi detectada a existência de canos para captação em várias localidades, quer em uso ou desuso, em ambas as ribeiras, além da ocorrência de canas nas margens em certos pontos, estradas cortando as linhas d'água, gerando obstruções, com pontes e manilhas. Em relação às alterações morfológicas, os locais de estudo não apresentam açudes ou pequenas barragens, apenas em um ponto na UFH F2, que apresenta pequenas paredes de pedra que dividem e protegem a agricultura.

Por meio dos dados obtidos, foram produzidas cartas comprovando a existência de alterações pontuais nas duas bacias, tais como obstruções por pontes e manilhas, e presença de canas nas margens. Elas refletiram negativamente na avaliação de sua qualidade ecológica, elevando consequentemente o valor KT.

Ambas as ribeiras sofrem pressão de estradas e do tecido urbano, pois são bacias que possuem praias balneares em sua foz e também nos seus entornos, como também é o caso da foz do rio Lizandro. Todas estas áreas contêm infraestrutura turística local com exploração de diversas atividades econômicas, especialmente para o lazer dos visitantes.

Com as informações referentes às pressões humanas nas bacias (Figura 6), foi feita a classificação KT, iniciando pelas áreas de todas as sub-bacias do Falcão e da Mata, e também nas linhas d'água de ambas as bacias, nas áreas inseridas dentro do buffer de 100 m gerado e calculado para cada UFH. Assim, ao relacionar as áreas das bacias às pressões humanas, obteve-se a percentagem de cada uma das pressões, tanto ligada às sub-bacias, quanto ao buffer de cada UFH.

O resultado da classificação final do índice KT contém não só os dados de pressão relativos às UFHs mas também os dados relacionados às sub-bacias de cada troço. Com isso, há uma diferença entre o KT total e o KT para cada UFH (Figura 6).

Os resultados da classificação KT por UFH contêm apenas os índices KT relacionados com cada UFH, excluindo os dados relacionados às sub-bacias de cada troço. Os resultados de cada variável de pressão KT estão dispostos na Figura 7.

Com o resultado de todas as variáveis de pressão foi feita sua classificação em relação às classes criadas, que variam de 1 (muito bom) a 5 (mau).

As UHFs F8 e F9, em vermelho, possuem a pior classificação ecológica encontrada (5 - Mau) devido à presença de terras irrigadas não só em sua sub-bacia, mas também dentro do buffer de $100 \mathrm{~m}$ em torno da linha d'água. Isto influiu negativamente na

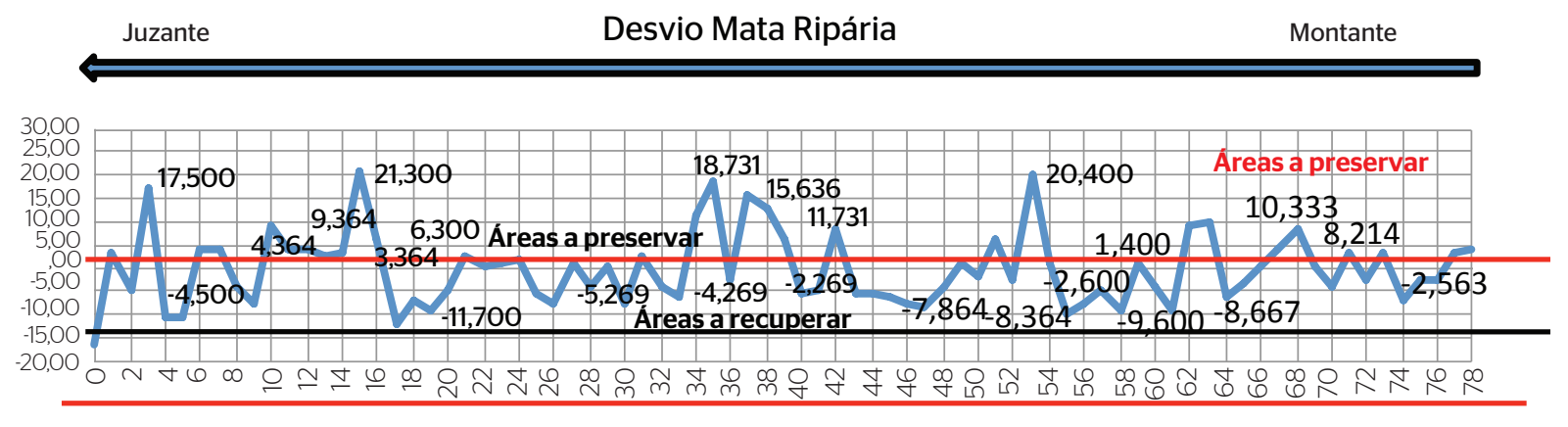

_ Desvio Mata Ripária

Áreas a recuperar

Figura 5 - Valores de desvio em relação à média de mata ripária por ponto da Ribeira da Mata. 


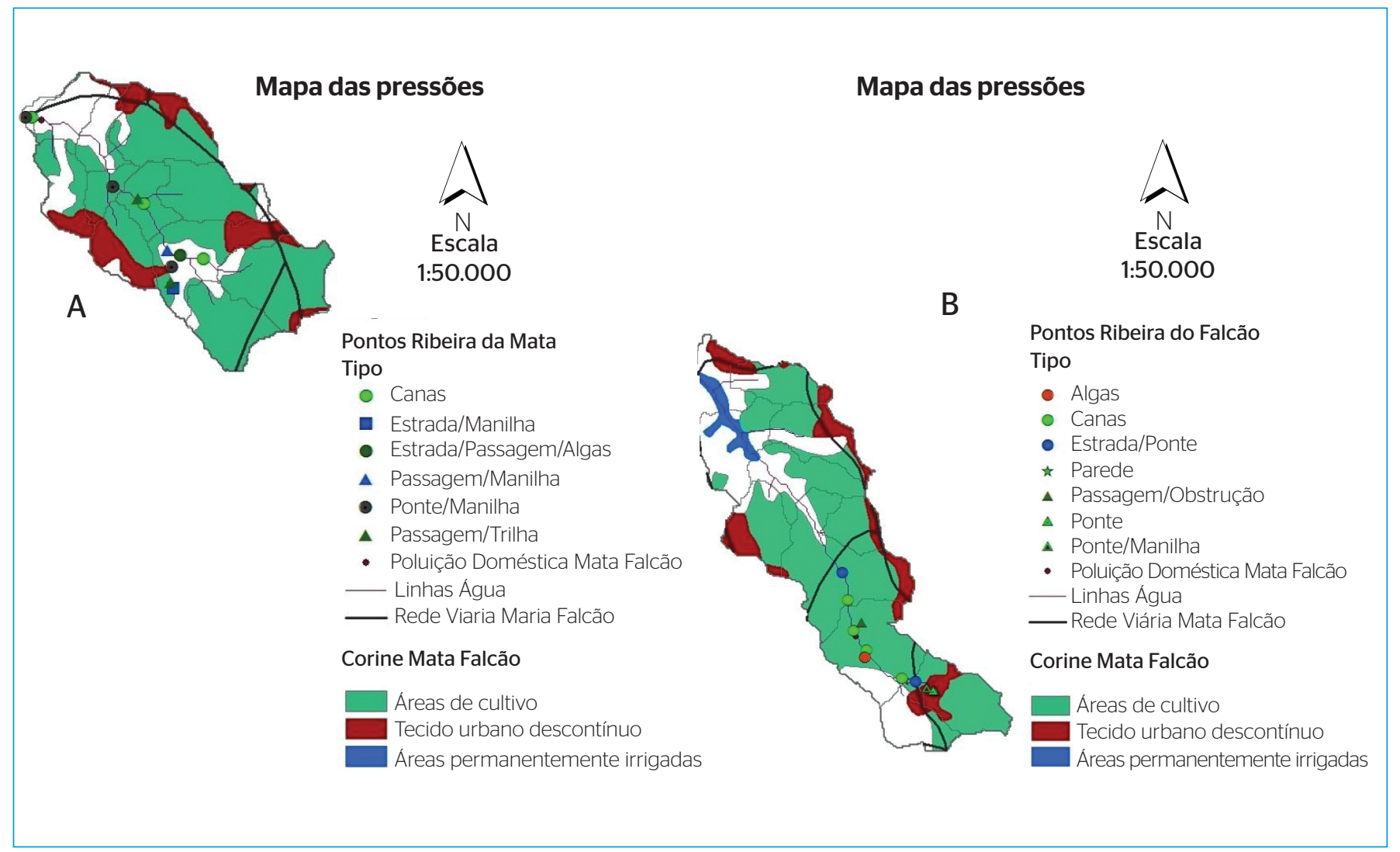

Figura 6 - Carta sintética de todas as pressões encontradas na bacia da Ribeira da Mata (A) e Ribeira do Falcão (B).

sua classificação, pois foi um dado contabilizado no ponderativo K5a. A classificação mais frequente foi "Mau”, por conta principalmente das elevadas percentagens de áreas agrícolas. Apenas duas UFHs apresentaram boa qualidade ecológica.

\section{DISCUSSÃO E CONCLUSÕES}

A classificação ecológica das pressões humanas identificadas nas bacias das ribeiras do Falcão e da Mata tornou factível a elaboração de propostas contendo as medidas de restauro prioritárias para que elas voltem a ter um funcionamento mais harmônico no ecossistema ribeirinho.

A legislação demanda um esforço neste sentido devido às políticas da DQA e do PGBH que todas as Administrações Regionais Hidrográficas precisam implementar e gerenciar nos próximos anos.

Segundo Zalewski (2000), para garantir a sustentabilidade no uso dos recursos hídricos é necessário não apenas reduzir ou eliminar a emissão de poluentes, mas ampliar o número de ferramentas de avaliação temporal da dinâmica da água no nível da bacia. Cortes et al. (2002) também apontam que além da necessidade da utilização destas ferramentas de análise para se garantir um desenvolvimento sustentável, práticas de gerenciamento para as áreas rurais precisam ser implementadas.
$\mathrm{Na}$ discussão dos resultados ficou evidente que diversas intervenções são necessárias para restaurar a qualidade ecológica das ribeiras, tais como remoção de obstáculos e obstruções por manilhas, pontes e canas (ZALEWSKI, 2000; AGUIAR JUNIOR \& CEOLIN, 2011). No entanto, como as duas bacias estudadas, especialmente a ribeira do Falcão, são caracteristicamente agrícolas, com culturas (irrigadas ou não) junto ao troço, diminuir o alto índice de poluição difusa deveria ser o foco das primeiras intervenções.

As inúmeras imagens demonstrando o desequilíbrio ambiental nas ribeiras, com excesso de algas verdes e azuis na massa d’água, evidenciam o estado de eutrofia do sistema fluvial, pois, como já foi demonstrado, a presença de algas é um bioindicador relevante da sua degradação.

As propostas de controle de poluição difusa, por meio da adoção de práticas agrícolas sustentáveis, visam à requalificação do sistema, diminuindo a entrada de poluentes. Além disso, é necessário restaurar a mata riparia e, dessa forma, aumentar a filtragem de nutrientes e a capacidade de infitração do solo.

Um programa para melhorar o gerenciamento das práticas agrícolas, com enfoque no desenvolvimento agrícola sustentável, requer o monitoramento da qualidade da água, com coleta e análise de dados, pois eles fornecem os parâmetros para o sucesso das atividades de gerenciamento dos recursos hídricos. 

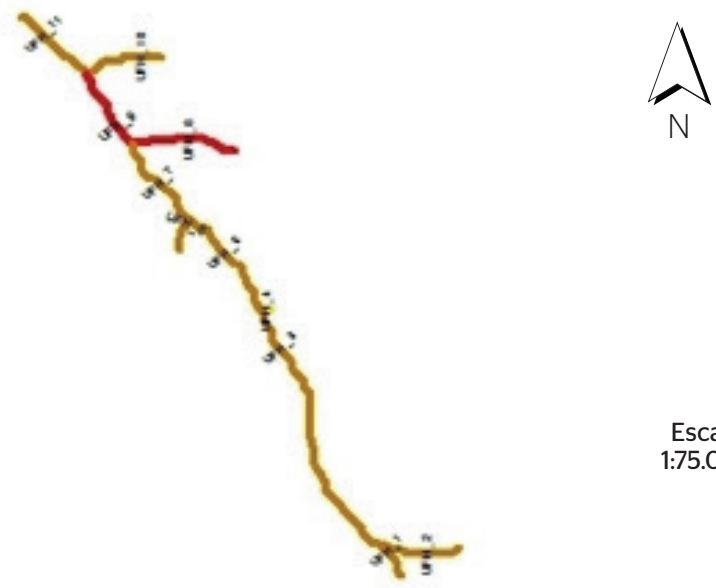

$\mathrm{N}$

Escala

$1: 75.000$

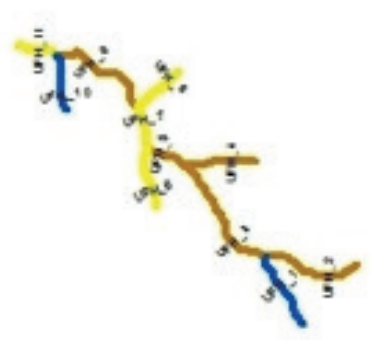

Linhas Água

Classificação KT Final

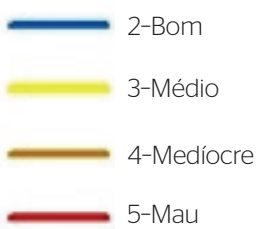

Figura 7 - Carta do resultado da classificação do índice KT por Unidades Fisiográficas Homogêneas.

O método de avaliação da poluição difusa por sensoriamento remoto e sistema de informações geográficas usando o SIG é uma alternativa viável, podendo ser aplicado para estabelecer estimativas e diagnósticos da situação ambiental em qualquer bacia hidrográfica ou região geográfica. O uso do SIG apresenta um grande potencial para ser empregado com grande êxito nos trabalhos de restauro fluvial. Por meio da classificação de imagem de satélite é possível analisar as mudanças de cobertura vegetal de uma área e, ainda, prever e localizar os impactos causados pela ação antropogênica, permitindo o gerenciamento mais eficiente e eficaz de bacias.

Além do SIG, a adoção do índice KT permitiu uma classificação dos dados e identificação das agressões mais presentes, o que é fundamental no planejamento de ações eficazes para a recuperação das bacias. O índice KT representa uma ferramenta eficiente para a gestão em diferentes escalas espaciais, particularmente no nível do segmento e da bacia hidrográfica, auxiliando na identificação das medidas de intervenção mais indicadas.

A tipologia e a forma de classificação do índice KT possibilitaram não apenas melhor conhecimento do estado de conservação do sistema fluvial, mas também uma previsão de sua resposta a futuras intervenções (ZALEWSKI, 2000). Além disso, ele foi um instrumento que permitiu a identificação dos segmentos que permaneceram preservados e que, portanto, precisam ser protegidos para evitar degradações futuras.

Com a própria capacidade do sistema fluvial de autodepuração e renovação, as ribeiras, após a aplicação das medidas de restauro, certamente apresentarão melhoria na qualidade ecológica e atingirão os objetivos definidos para os estados membros pela DQA.

Para obras de recuperação de canais fluviais é necessário o conhecimento técnico da dinâmica das bacias hidrográficas, sendo que qualquer intervenção neles ocasiona algum efeito imediato, a médio ou longo prazo sobre a bacia como um todo, de acordo com estudos de Cortes et al. (2002) e Aguiar (2010; 2012).

Finalmente, espera-se que esta pesquisa traga novas perspectivas de uso e, consequentemente, melhor qualidade ecológica para as bacias do Falcão e da Mata. No planejamento da gestão dos recursos hídricos, as diversas ferramentas disponíveis para geoprocessamento, quando aliadas à metodologia KT, são fundamentais em bacias nas quais ainda não há monitoramento ou qualquer tipo de estudo sobre os impactos ambientais. 


\section{REFERÊNCIAS}

AGUIAR JUNIOR T.R. (2010) Distribuição potencial do alytes cisternasii em Portugal continental: modelo conceitual da estrutura de informação geográfica. Oecologia Australis, v. 14, n. 4, p. 808-817.

AGUIAR JUNIOR T.; CEOLIN, L.P.W. (2O11) Estudo sócio-ambiental dos recursos pesqueiros do litoral alentejano. Revista Eletrônica de Biologia, v. 4, n. 2, p. 93-101.

BORJA, P.C.; MORAES, L.R.S. (2003) Indicadores de saúde ambiental com enfoque para a área de saneamento: aspectos conceituais e metodológicos. Revista Engenharia Sanitária e Ambiental, v. 8, n. 2 , p. $13-25$.

CORTES, R.M.V.; OLIVEIRA, S.V.; CABRAL, D.A.; SANTOS, S.; FERREIRA, T. (2002) Different scales of analysis in classifying streams: from a multimetric towards an integrated system approach. Large Rivers, v. 13, n. 3-4, p. 209-224.

FERNANDES, M.R.; FERREIRA, M.T.; HUGHES, S.; CORTES, R.M.V.; SANTOS, J.M., PINHEIRO, P.J. (2007) Pré-classificação da qualidade ecológica na bacia de Odelouca e sua utilização em directrizes de restauro. Recursos Hidricos, v. 28, p. 15-24.

MUHAR, S. (1996) Habitat improvement of Austrian rivers with regard to different scales. Regulated Rivers: ResEarch \& Management, v. 12, n. 4-5, p. 471-482.

ZALEWSKI, M. (2000) Ecohydrology - the scientific background to use ecosystem properties as management tools toward sustainability of water resources. Ecological Engineering, v. 16, n. 1, p. 1-8. 